\title{
Herbal Use and Perceptions among Patients with Type 2 Diabetes Mellitus in Kuwait
}

\author{
Ibrahim El Bayoumy ${ }^{1,2}$ (D), Walid Dawod ${ }^{1}$ \\ ${ }^{1}$ Tanta Faculty of Medicine, Tanta, Egypt \\ ${ }^{2}$ Ministry of Health, Farwaniya, Kuwait \\ Email: ibrahim.elbayoumy@med.tanta.edu.eg,welydavid@yahoo.com
}

How to cite this paper: El Bayoumy, I. and Dawod, W. (2022) Herbal Use and Perceptions among Patients with Type 2 Diabetes Mellitus in Kuwait. Journal of Diabetes Mellitus, 12, 50-62.

https://doi.org/10.4236/jdm.2022.121006

Received: November 15, 2021

Accepted: January 16, 2022

Published: January 19, 2022

Copyright $\odot 2022$ by author(s) and Scientific Research Publishing Inc. This work is licensed under the Creative Commons Attribution International License (CC BY 4.0).

http://creativecommons.org/licenses/by/4.0/ (c) (i) Open Access

\begin{abstract}
Herbal medicine has become a popular treatment among patients with chronic diseases worldwide. Many patients with diabetes mellitus use herbal medicine without consulting their health professionals. The aim of this study was to assess the prevalence, pattern of use, and perceptions in type 2 diabetes patients using herbal medicine. It was conducted between $1^{\text {st }}$ January 2019 and end of June 2019 diabetes clinic in Farwaniya Hospital in Kuwait. In this cross sectional quantitative study, 350 patients were asked to complete questionnaire administered by nurses. The study found that $30.6 \%$ of sample used herbal medicine-women more than men. Black cumin (habba soda) i.e. Nigella sativa was the most common herb used by diabetic patients. The study revealed that $70 \%$ of herbal medicine users had poor glycemic control $\left(\mathrm{HbA}_{1} \mathrm{c}\right.$ $\geq 7 \%$ ). Diabetic complications were greater in herbal users than in those receiving conventional therapy. The study also showed that $95.3 \%$ of herbal medicine users did not inform their treating doctors. Our conclusion was that herbal medicine users needed to increase their awareness and education about the risks and complications of herbal medicine.
\end{abstract}

\section{Keywords}

Herbal Medicine, Complimentary Medicine-Type 2 Diabetes Mellitus, Perceptions, Kuwait

\section{Introduction}

The World Health Organization (WHO) defines complementary medicine as a diverse health practice, which included the use of herbal medicines, mineral-based medicines and animal parts which are used singly or in combination to diagnose or prevent or treat illness and to maintain well-being [1]. 
Type 2 diabetes mellitus is highly prevalent in Gulf countries, and prevalence of diabetes mellitus in Kuwait is $21.1 \%$ [2]. It is well known that diabetes mellitus is associated with significant morbidity and mortality, from various micro vascular complications such as retinopathy, nephropathy and neuropathy and as well as macro vascular complications such as ischemic heart disease, stroke and peripheral vascular disease [3].

Complementary and Alternative Medicine (CAM) is widely used throughout the world especially by patients with chronic diseases such as type 2 diabetes mellitus. In the United States, the Centers for Disease Control and Prevention report that $40 \%$ of adults and $10 \%$ of children have used complementary treatment [4]. Australian data, published in 2007 have suggested that $64 \%$ of the people had used one or more modes of CAM in the previous 12 months [5]. The proportion of patients using CAM over one year was 23\% in Denmark and $49 \%$ in France [6]. In Gulf countries such as Saudi Arabia, 30\% of patients with diabetes mellitus had used herbal medicine to treat their condition [7]. It is widely believed that some herbal remedies provide symptomatic relief and help in the prevention of complication from diabetes mellitus. Some are proven to help in regenerating pancreatic beta cells in overcoming insulin resistance and in improving glycemic control in diabetic patients [3].

The chronic nature of diabetes mellitus and its complications motivate patients to use alternative medicine to treat their condition [8]. Patients decide to use complementary medicine for a variety of reasons including dissatisfaction with conventional treatment, the side effects of prescribed drugs and high costs of the drugs and most drugs have side effects and high costs of such drugs [9] [10]. In some cases these traditional methods of treatment coincide with patients' values, or spiritual and religious and beliefs regarding the nature and the meaning of illness and death [11] [12].

\section{Aim of the Study}

This study aimed to investigate the prevalence of type 2 diabetes patients using herbal or alternative medicine use Kuwait among type 2 diabetes mellitus patients. This investigation aimed to provide essential evidence to guide individuals and decision makers.

\section{Patients and Methods}

This is a cross-sectional quantitative study that assessed the prevalence, and type of herbal medicine used to treat type 2 diabetes and was conducted between January 2019 and end of June 2019 in the diabetes clinic at Farwaniya Hospital Kuwait.

\section{Study Population}

Sample size and recruitment strategies.

The sample size was calculated according to the equation used in cross-sectional 
studies and surveys.

$$
\text { Sample size } n=\frac{z_{1}-\alpha^{2} / P^{(1-P)}}{d^{2}}
$$

where $n=$ number to be sampled

$Z^{2}=(1.96)^{2}$ for $95 \%$ confidence

$P=$ "best guess" for prevalence

$d=$ Absolute i.e. (Maximum tolerable error for the prevalence estimate)

Sample size in this study assumes a 35\% prevalence of herbal medicine use of herbal medicine in people with type 2 diabetes mellitus is 350 patients.

Patients were selected by systematic random sampling Data were collected face-to-face by the diabetes consultant at the clinic using a 24-item questionnaire adapted and modified from previously validated studies on herbal medicine use. The structured questionnaire was composed of socio-demographic variables and questions about management of diabetes mellitus to capture knowledge, attitudes and beliefs.

\section{Inclusion and Exclusion Criteria}

Participants were male and female patients aged 18 or over who had been diagnosed with type 2 diabetes at least a year ago, and had HbA1c of more than $6.5 \%$, fasting blood glucose of $\geq 123 \mathrm{mg} / \mathrm{dl}$ and post-prandial blood sugar of $\geq 200$ $\mathrm{mg} / \mathrm{dl}$ recorded on 2 occasions. Participants were selected providing they were conventional medications which was described by the diabetes doctor (drugs or insulin or mixed) for diabetes, had good cognitive functions and successfully completed the interview process. Exclusion criteria included patients not diagnosed with diabetes mellitus before their clinic visit, those who had not received oral anti-diabetic drugs or insulin, and patients experiencing difficulties in understanding the questions.

Ethical approval number $00769 \mathrm{MOH}$ was obtained from the Ethics Committee of the Ministry of Health in Kuwait. Informed verbal and written consent was also obtained from all participants.

\section{Statistical Analysis}

The collected data were coded, entered and analyzed using SPSS software version 23. Data were presented as frequencies and percentages, means and standard deviations. The Chi-square test was used to show the significance of association between different variables and the use of herbal medicine. A P-value of less than 0.05 was considered significant.

\section{Results}

\subsection{Socio-Demographic Data}

A total of 350 patients with type 2 diabetes were included in this study. 30.7\% reported using herbal medicine in their therapy regimen (107 NIDDM). Half of 
these patients were aged $40-59$ and about $31.6 \%$ of them were aged over 59 years (Table 1 ).

Women used herbal remedies more than men (56.1\% compared to $43.9 \%$ ) with significant statistical difference between patients using and not using herbal remedies (P-value 0.001). 51.4\% of herbal medicine users had 12 years or more of education. $74.8 \%$ were Kuwaiti nationals. There was no significant statistical difference regarding educational level between users and non-users of remedies (P-value $\geq 0.05$ ). (Table 1) Patients with an average monthly income of between 500 and 1000 Kuwaiti dinars were split into $46.7 \%$ herbal medicine users and $33.7 \%$ non-users. There was significant statistical difference between users and non-users of herbal medicine (P-value 0.00001) (Table 1). A family history of

Table 1. Socio-demographic characteristics of herbal users and non-herbal users.

\begin{tabular}{|c|c|c|c|c|}
\hline & $\begin{array}{l}\text { Using herbal } \\
\text { remedies }\end{array}$ & $\begin{array}{l}\text { Not using herbal } \\
\text { remedies }\end{array}$ & $\mathrm{X}^{2}$ & $\mathrm{P}$-value \\
\hline Age (years) & $\mathrm{N}=107$ & $\mathrm{~N}=243$ & 5.187 & 0.075 \\
\hline$<40$ & $20(18.7)$ & $43(17.7)$ & & \\
\hline $40-59$ & $54(50.5)$ & $95(39.1)$ & & \\
\hline$>59$ & $33(30.8)$ & $105(43.2)$ & & \\
\hline \multicolumn{5}{|l|}{ Sex } \\
\hline Male & $47(43.9)$ & $150(61.7)$ & 9.576 & 0.001 \\
\hline Female & $60(56.1)$ & $93(38.3)$ & & \\
\hline \multicolumn{5}{|l|}{ Education } \\
\hline Illiterate & $22(20.6)$ & $51(21.0)$ & 0.283 & 0.868 \\
\hline$<12$ years of education & $30(28.0)$ & $70(28.8)$ & & \\
\hline$\geq 12$ years of education & $55(51.4)$ & $122(50.2)$ & & \\
\hline Nationality & & & 2.989 & 0.838 \\
\hline Kuwaiti & $80(74.8)$ & $201(82.7)$ & & \\
\hline Non-Kuwaiti & $27(25.2)$ & $42(17.3)$ & & \\
\hline \multicolumn{5}{|l|}{ Monthly Income } \\
\hline$<500 \mathrm{KD}$ & $25(23.4)$ & $60(24.7)$ & 34.518 & $<0.00001$ \\
\hline $500-1000 \mathrm{KD}$ & $50(46.7)$ & $82(33.7)$ & & \\
\hline$\geq 1000 \mathrm{KD}$ & $32(29.9)$ & $101(41.6)$ & & \\
\hline \multicolumn{5}{|l|}{ Occupation } \\
\hline Employed & $70(65.4)$ & $150(61.7)$ & 0.938 & 0.626 \\
\hline Unemployed & $10(9.3)$ & $20(8.2)$ & & \\
\hline Retired & $27(25.2)$ & $73(30.1)$ & & \\
\hline \multicolumn{5}{|l|}{ Marital status } \\
\hline Married & $90(84.1)$ & $220(90.5)$ & 2.866 & 0.090 \\
\hline Unmarried & $17(15.9)$ & $23(9.5)$ & & \\
\hline
\end{tabular}


diabetes mellitus was recorded for $58 \%$ of diabetic patients who used herbal medicine compared to $53.4 \%$ of diabetic patients who were not using herbal medicine. There was no significant statistical difference between the two groups $(\mathrm{P}$-value $=0.441)($ Table 2$)$. Most herbal users and non-users had had diabetes mellitus for more than five years ( $60.7 \%$ and $58.4 \%$ respectively). Follow-up of glycemic status was not regular for $70 \%$ of diabetic patients using herbal medicine compared to $34.2 \%$ for non-users. There was significant statistical difference between the two groups $(\mathrm{P}$-value $<0.00001)$.

\subsection{Types of Herbal Remedies Used}

In regard to the most popular herbs, 17 diabetic patients were using a mixture of herbal remedies prepared by a herbalist (15.9\%), followed by 15 patients using Black cumin (Habba soda or Nigella sativa). 12 patients used Cinnamon (Darcien or Cinnamomum zeylanicum Blume. 11 used garlic, 10 used Fenugreek (Trigonella foenumgraecum) and 10 were using Bitter apple (Citrullus colocynthis). Seven patients used onion and five used Aloe vera (Table 3).

\subsection{Diabetes Mellitus Control and Compliance and Diabetes Complications}

Glycemic status was not controlled for $71 \%$ of herb users compared to $40 \%$ of non-users, so that diabetic complications were more common for herb users (71.1\%) compared to $17 \%$ for non-users. However, there was significant statistical difference between the two groups ( $\mathrm{P}$ value $<0.00001$ ) (Table 4).

Table 2. History of diabetes, duration and continuity of care in patients.

\begin{tabular}{|c|c|c|c|c|}
\hline Variable & $\begin{array}{c}\text { Using herbs } \\
\text { No }=107\end{array}$ & $\begin{array}{l}\text { Not using } \\
\text { No }=243\end{array}$ & $\mathrm{X}^{2}$ & P-Value \\
\hline Family history of diabetes & No $\%$ & No $\%$ & & \\
\hline Yes & $62(58)$ & $130(53.4)$ & 0.593 & 0.441 \\
\hline No & $45(42)$ & $113(46.5)$ & & \\
\hline \multicolumn{5}{|l|}{ Duration of diabetes } \\
\hline$<5$ years & $42(39.3)$ & $101(41.6)$ & 0.166 & 0.684 \\
\hline $5+$ years & $65(60.7)$ & $142(58.4)$ & & \\
\hline \multicolumn{5}{|l|}{ Continuity of care } \\
\hline Follow-up always in the same clinic & $40(37.4)$ & $97(40.0)$ & 0.199 & 0.656 \\
\hline Follow-up in different centers & $67(62.6)$ & $146(60.0)$ & & \\
\hline \multicolumn{5}{|l|}{ Regularity of follow-up } \\
\hline Regular & $32(30.0)$ & $160(65.8)$ & 53.519 & $<0.00001$ \\
\hline Not regular & $75(70.0)$ & $83(34.2)$ & & \\
\hline \multicolumn{5}{|l|}{ Number of annual follow up visits } \\
\hline$<6$ per year & $61(57.0)$ & $70(28.8)$ & 25.228 & $<0.00001$ \\
\hline $6+$ per year & $46(43.0)$ & $173(71.2)$ & & \\
\hline
\end{tabular}


Table 3. Herbal medicine used to treat diabetes mellitus.

\begin{tabular}{|c|c|c|c|c|}
\hline English name & Local name & Latin name & $\begin{array}{l}\text { Using remedy } \\
\text { No }=107\end{array}$ & $\%$ \\
\hline Fenugreek & Helbah & $\begin{array}{c}\text { Trigonella } \\
\text { foenum-graecum }\end{array}$ & 10 & 9.3 \\
\hline Black cumin & Habba Soda & Nigella sativa L & 15 & 14.1 \\
\hline Cinnamon & Darcein & $\begin{array}{c}\text { Cinamonum } \\
\text { zeylanicum Blume }\end{array}$ & 12 & 11.2 \\
\hline Bitter apple & HanThal & Citrullus colocynthis & 10 & 9.3 \\
\hline White lupine & Termes & Lupinus albus & 6 & 5.6 \\
\hline Garlic & Thum & Allium sativuon & 11 & 10.3 \\
\hline Onion & Basal & Allium cepa & 7 & 6.5 \\
\hline Aloe vera & Sabr & Aloe vera $\mathrm{L}$. & 5 & 4.7 \\
\hline Worm wood & Sheeh & Artemisia judaica & 5 & 4.7 \\
\hline $\begin{array}{c}\text { Herbal mix Prepared by } \\
\text { Herbalist }\end{array}$ & & & 17 & 15.9 \\
\hline More than one type & - & - & 9 & 8.4 \\
\hline
\end{tabular}

Table 4. Diabetes mellitus control, complications and compliance.

\begin{tabular}{|c|c|c|c|c|}
\hline Variable & $\begin{array}{c}\text { Using herbs } \\
\text { No }=107 \\
\text { No } \%\end{array}$ & $\begin{array}{c}\text { Not using } \\
\text { No }=243 \\
\text { No } \%\end{array}$ & $\mathrm{X}^{2}$ & P-Value \\
\hline \multicolumn{5}{|l|}{ Glycaemic control } \\
\hline Controlled $\mathrm{HbA} 1 \mathrm{c}<7 \%$ & 3129 & 14560 & 28.01 & $<0.00001$ \\
\hline Not-controlled HbA1c $\geq 7 \%$ & 7671 & 9840 & 40 & \\
\hline \multicolumn{5}{|l|}{ Type of treatment } \\
\hline On diet only & 32.8 & 83.3 & 0.255 & 0.968 \\
\hline Oral tablets & 8074.8 & 18375.3 & & \\
\hline Insulin & 54.7 & 135.3 & & \\
\hline Mixed & 1917.7 & 3916.1 & & \\
\hline \multicolumn{5}{|l|}{ Regularity of treatment } \\
\hline On diet only & 32.8 & 52.1 & 16.938 & 0.0002 \\
\hline Regular medical treatment & 109.3 & 7330.0 & & \\
\hline Irregular medical treatment & 9487.9 & 16567.9 & & \\
\hline \multicolumn{5}{|l|}{ Complications of DM } \\
\hline Absent & 3128.9 & 20283.1 & 93.723 & $<0.00001$ \\
\hline Present & 7671.1 & 4116.9 & & \\
\hline
\end{tabular}

The majority of diabetic patients in both groups were using oral tablets to control their metabolic state $(74.8 \%$ in herbal users and $75.3 \%$ in non herbal us- 
ers respectively) followed by mixed oral tablets and insulin in $17.7 \%$ in herbal users compared to 16.1 in non herbal users followed by insulin and diet therapy with no significant statistical difference between herbal and non herbal users ( $\mathrm{p}$ value $=0.968)($ Table 4$)$.

The majority of herbal users used their conventional treatment on an irregular basis 94 patients while 73 diabetic patients of non herbal users were using their drugs of their treatment regularly and there was significant statistical difference between both groups (P value $\leq 0.0002$ ) (Table 4).

Diabetes complications as nephropathy, retinopathy and neuropathy and hypertension were more prevalent in herbal users as these complications were observed in $76 \%$ of herbal users compared to $41 \%$ in non herbal users with significant statistical association between both groups ( $\mathrm{P}$ value $\leq 0.00001$ ) (Table 4).

\subsection{Patterns, Attitudes and Perceptions}

Most of the herbal medicine users $69.2 \%$ of them got most of their information about herbal medicines from friends. $14 \%$ got information from family members and $12 \%$ from $\mathrm{TV}$, radio or the internet. $4.7 \%$ reported choosing their herbal medicines based on their own knowledge (Table 5). $46.4 \%$ of the herbal medicine users reported using herbal medicine to support their treatment of diabetes by conventional treatment, $9 \%$ reported a loss of confidence with prescribed drugs used to manage their condition. 9.3\% reported using herbs to avoid diabetic complications. $65.4 \%$ of herbal medicine users said they had not experienced side-effects from using it. 30 patients (28\%) said they had experienced side effects.

Table 5. Perceptions and attitudes of use of herbal medicine.

\begin{tabular}{lcc}
\hline & No & $\%$ \\
\hline Source of information & 5 & 4.7 \\
Self option & 74 & 69.2 \\
Friends & 15 & 14.0 \\
Family & 13 & 12.1 \\
Media & & \\
\hline Indications for use & 50 & 46.7 \\
Supportive & 31 & 29.0 \\
Loss of confidence with drug & 10 & 9.3 \\
To avoid complications & 16 & 15.0 \\
More than one cause & & \\
\hline Side effects of herbal medicine & 30 & 28.0 \\
Yes & 70 & 65.4 \\
No & 7 & 6.5 \\
Not sure & & \\
\hline
\end{tabular}




\section{Continued}

\begin{tabular}{ccc}
\hline Use alongside with conventional treatment & & \\
Yes & 64 & 59.8 \\
No & 35 & 32.7 \\
Sometimes & 8 & 7.5 \\
\hline Frequency of use & & \\
Daily & 42 & 39.3 \\
Weekly & 50 & 46.7 \\
Other & 15 & 14.0 \\
\hline Satisfaction & & 74.8 \\
Yes & 80 & 18.7 \\
No & 20 & 6.5 \\
Note sure & 7 & \\
\hline Informing the clinic doctor & & 4.7 \\
Yes & 5 & 95.3 \\
No & 102 & \\
\hline
\end{tabular}

$60 \%$ were using herbal remedies along side with drugs or insulin and $32.7 \%$ were using herbal remedies as a single treatment mode for their diabetes. Eight patients were using herbal remedies infrequently (Table 5).

Most herbal medicine users $(74.8 \%)$ were satisfied with the use of herbal medicine and $20 \%$ were not satisfied. Seven patients $6.5 \%$ were unsure about side effects of herbs. $95.3 \%$ of herbal medicine users had not informed their hospital doctors (Table 5).

\section{Discussion}

The use of herbal therapy is a common practice in chronic diseases both in developed and developing countries [13] [14] [15] [16]. This use may be attributed to the long-term suffering of patients or to the failure of medical treatment to bring rapid and long-lasting relief and control of these diseases, also people believe that herbal medicine is more natural than modern drugs [17].

Herbal medicine is frequently used by patients with diabetes mellitus to help them manage this chronic disease [18].

The use of herbs in treatment of diabetes is attributed to several mechanisms of action like in Fenugreek the hypoglycemic effect may be mediated through stimulating insulin synthesis and/or secretion from the beta pancreatic cells of langerhans. Prolonged administration of the same dose of the active principle for 30 days to the severely diabetic rabbits lowered fasting blood glucose significantly, but could elevate the fasting serum insulin level to a much lower extent, which suggests an extra-pancreatic mode of action for the active principle. The effect may also be by increasing the sensitivity of tissues to available insulin. The 
hypoglycemic effect was observed to be slow but sustained, without any risk of developing severe hypoglycemia [19]. Nigella sativa are used as seeds or crude oil in treatment of diabetes mellitus as it exhibits remarkable ability to increase insulin sensitivity and induce proliferation of beta cells of pancreas in diabetic rats [20]. In human, it was reported that NS use after 30 days of use is associated with improvement in fasting and post prandial glucose levels [21].

For Cinnamon that is a herb used widely in Arabic countries. Among the components of cinnamon, cinnamaldehyde significantly and dose-dependently decreases the plasma glucose concentration of streptozotocin-induced diabetic rats [22].

Regarding the mechanism underlying these effects, it was reported that cinnamon extracts promote the transportation of glucose by glucose transporter 4 in brown adipose tissue and muscles. Clinical research studies support the positive effects of cinnamon on both types 1 and 2 diabetes mellitus [23] [24] [25]. The effect of Citrullus colocynthis hydraulic extract (Bitter apple) on rats, which had diabetes induced by streptozocin and normoglycemic rats was evaluated in a research, the results showed the alleviated blood glucose level of diabetic rats using a specific dose of the extract. However, the extract had no significant impact on blood glucose level in normoglycemic rats [26]. The literature review revealed that 50 patients with type 2 diabetes were evaluated for two months in a clinical trial. In this research, two groups of intervention $(n=25)$ and control (n =25) received $100 \mathrm{mg}$ capsules of $C$. colocynthis extract and placebo three times daily, respectively. According to the results, a significant reduction was observed in the level of fasting blood sugar and HbAlc of the subjects in the intervention group [27].

A number of studies have focused on the ability of onion and garlic to ameliorate diabetes, with many of them reporting both hypoglycemic and hypolipidemic effects in animal models of chemically induced no insulin-dependent diabetes [28] [29]. However, the effects of ripe onion juice on hypoglycemic activity and on anti-diabetic activity have not been evaluated.

We found that $30.6 \%$ of diabetic patients in our study used herbal medicine. This finding is consistent with the study of Al Saeedi et al., 2003 [7] in Saudi Arabia, where the prevalence of the use of herbal medicine among patients with diabetes was $30.1 \%$ of the studied sample.

The study by Alami et al. [30] in Morocco revealed that the prevalence of use of herbal medicine in diabetic patients was high (54.8\%). In Gulf countries such as Saudi Arabia, a 2002 study by Al-Rowais et al. [17] reported that $17.4 \%$ of 300 diabetic patients were using herbal medicine. In 2008, a Kuwait study by Awad et al. [31] reported that only $13 \%$ of the diabetic patients (104 diabetic patients) were using herbal medicine. Our study revealed that half of the diabetic patients using herbal medicine were aged between 40 and 59 years, and $30 \%$ were 59 or over. This finding coincides with the studies of Al-Rowais [17] and Al-Saeedi et al. 2003 [7]. 
We found that employment status and level of education did not have statistical significance associated with the use of herbs. This result is not consistent with the findings of other studies. As one example, study of Kumar et al. [32] found that in an Indian survey, a higher level of education and socio-economic status were significant positive correlates with use of herbal medicine in India.

A significant relationship was observed in many studies between a higher prevalence of use of herbal medicine and higher ages, female gender, higher education, longer duration of diabetes and high rates of diabetes complications [8]. All these factors are consistent in our results with the exception of educational level. In this regard, our results are consistent with the 2013 Malaysian study by Ching et al. [15], where the educational level of the diabetic patients had no significant association with herbal medicine use in diabetic patients.

In our study, $71 \%$ of diabetic patients using herbs had poor glycemic control and the frequency of complications was higher than for patients on conventional treatment. This may be attributed to the fact that, most of herbal users did not use herbs on daily basis and in an irregular way and may be some times as monotheray without using ant diabetic drugs described by the treating doctor also herbal users have a higher degree of regularity in follow-ups for their glycemic status in primary health care centers and outpatient clinics in Kuwait. Most herbal medicine users (95\%) did not inform their consultants about their use of herbs for managing their diabetes mellitus. This finding coincides with the results of Khalaf et al. [13] and Argaez-Lopez et al. [33]. This may be attributed to limited time during a clinic visit, to inadequate doctor-patient communication during consultations or to a fear of a negative attitude from doctors. Clinicians may also fail to ask patients about the use of herbal medicine.

\section{Conclusions}

This study assessed patients' use perspectives and practices regarding the use of herbal medicine in the management of diabetes. About one-third of diabetic patients have reported such use. Most of the herbal medicines were plant products that were affordable and widely available locally. Although herbal medicines have potential benefits, they also have potential adverse effects. There is currently limited knowledge of the physiological effects of most herbal medicines that were widely used, so it is not possible to assess whether these medicines were beneficial, harmful, or both. In view of this, the findings reveal a need for further research to identify the bioactive compounds present in these medicinal plants and to determine their efficacy at a physiological level.

Patient education is a cornerstone item in improving the knowledge of diabetic patients about the benefits and side effects of these herbs and how to use these herbs and safe dose and should be used with diabetes conventional therapy and not used alone and used in regular basis, and also we need the pharmaceutical agencies to do more studies about the activity and side effects of these herbs in their future research. 


\section{Limitations of the Study}

The limitation of this study, may be small sample size as if large sample size is large and including multi centers in Kuwait, we were able to estimate the actual prevalence of the herbal use in Kuwait, and this will be done in my future research, also we did not stress on the major side effects of these herbs as many patients may deny the presence of these side effects as they are afraid to tell their treating doctors about their use of herbs and did not report about side effects of these herbs.

\section{Conflicts of Interest}

The authors declare no conflicts of interest regarding the publication of this paper.

\section{References}

[1] Khatib, O.M.N (2006) Guidelines for Prevention, Management and Care of Diabetes Mellitus. EMRO Technical Publications Series No. 32, World Health Organization, Geneva.

[2] Abu El-Asrar, A.M., Al-Rubeaan, K.A., Al Amro, S.A., Kangave, D. and Mohairam, O.A. (1999) Risk Factors for Diabetic Retinopathy among Saudi Diabetics. International Ophthalmology, 22, 1072-1076. https://doi.org/10.1023/A:1006240928938

[3] Jarald, E., Joshi, S.B. and Jain, D. (2008) Diabetes and Herbal Medicines. Iranian Journal of Pharmacology and Therapeutic, 7, 97-106.

[4] Barnes, P.M., Powell Griner, E., McFann, K. and Nahin, R.L. (2003) Complementary and Alternative Medicine Use among Adults: United States, 2002. Advance Data, 27, 1-19.

[5] Xue, C.C., Zhang, A.L., Lin, V., Da Costa, C. and Story, D.E. (2007) Complementary and Alternative Medicine Use in Australia: A National Population-Based Survey. The Journal of Alternative and Complementary Medicine, 13, 643-650. https://doi.org/10.1089/acm.2006.6355

[6] Fisher, P. and Ward, A. (1994) Complementary Medicine in Europe. BMJ, 309, 107-111. https://doi.org/10.1136/bmj.309.6947.107

[7] Al-Saeedi, M., El Zubier, A.G., Bahnassi, A.A. and Al Dawood, K.M. (2003) Patterns of Belief and Use of Traditional Remedies by Diabetic Patients in Mecca, Saudi Arabia. Eastern Mediterranean Health Journal, 9, 99-107. https://doi.org/10.26719/2003.9.1-2.99

[8] Chang, H.Y., Wallis, M. and Tiralongo, E. (2007) Use of Complementary and Alternative Medicine among People Living with Diabetes: Literature Review. Journal of Advanced Nursing, 58, 307-319. https://doi.org/10.1111/j.1365-2648.2007.04291.x

[9] Bishop, F., Perscott, P., Chan, Y.K., Saville, J., Von Elm, E. and Lewith, G.T. (2010) Prevalence of Complementary Medicine Use in Pediatric Cancer: A Systematic Review. Pediatrics, 125, 768-776. https://doi.org/10.1542/peds.2009-1775

[10] Ceylan, S., Azal, O., Taslipinar, A., Turker, T., Acikel, C.H. and Gulec, M. (2009) Complementary and Alternative Medicine Use among Turkish Diabetes Patients. Complementary Therapies in Medicine, 17, 78-83.

https://doi.org/10.1016/j.ctim.2008.07.003 
[11] Verhoef, M.J., Balneaves, L.G., Boon, H.S. and Vroegindewey, A. (2005) Reasons for and Characteristics Associated with Complementary and Alternative Medicine Use among Adult Cancer Patients: A Systematic Review. Integrative Cancer Therapies, 4, 274-286. https://doi.org/10.1177/1534735405282361

[12] Lee, M.S., Lee, M.S., Lim, H.J. and Moon, S.R. (2004) Survey of the Complementary and Alternative Medicine among Korean Diabetes Mellitus Patients. Pharmacoepidemiology and Drug Safety, 13, 167-171. https://doi.org/10.1002/pds.877

[13] Khalf, A.J. and Whiteford, D.L. (2010) The Use of Complementary and Alternative Medicine by Patients with Diabetes Mellitus in Bahrain: A Cross-Sectional Study. BMC Complementary Medicine and Therapies, 10, Article No. 35. https://doi.org/10.1186/1472-6882-10-35

[14] Naja, F., Mousa, D., Alameddine, M., Shoaib, H. and Mourad, Y. (2014) Prevalence and Correlates of Complementary and Alternative Medicine Use among Diabetic Patients in Beirut, Lebanon: A Cross-Sectional Study. BMC Complementary Medicine and Therapies, 14, Article No. 185. https://doi.org/10.1186/1472-6882-14-185

[15] Ching, S.M., Zakaria, Z.A., Paimin, F. and Jalalian, M. (2013) Complementary Alternative Medicine Use among Patients with Type 2 Diabetes Mellitus in the Primary Care Setting: A Cross Sectional Study in Malaysia. BMC Complementary and Alternative Medicine, 13, Article No. 148. https://doi.org/10.1186/1472-6882-13-148

[16] James, P., Wardle, L., Amie, S. and Adams, J. (2018) Traditional, Complementary and Alternative Medicine Use in Sub-Saharan Africa: A Systematic Review. BMJ Global Health, 3, e000895. http://dx.doi.org/10.1136/bmigh-2018-000895

[17] Al-Rowais, N.A. (2012) Herbal Medicine in the Treatment of Diabetes Mellitus. Saudi Medical Journal, 23, 1327-1331.

[18] WHO (World Health Organization) (2004) WHO Guidelines on Developing Information on Proper Use of Traditional, Complementary and Alternative Medicine. World Health Organization, Geneva. https://apps.who.int/iris/handle/10665/42957

[19] Puri, D., Prabhu, K.M. and Murthy, P.S. (2002) Mechanism of Action. Mechanism of Action of Hypoglycaemic Principle Isolated from Fenugreek Seeds. Indian Journal of Physiology and Pharmacology, 46, 457-462.

[20] Benhaddou-Andaloussi, A., Martineau, L.C., Spoor, D., Vuong, T., Leduc, C., Joly, E., et al. (2008) Antidiabetic Activity of Nigella sativa Seed Extract in Cultured Pancreatic $\beta$-Cells, Skeletal Muscle Cells and Adipocytes. Parmaceutical Biology, 46, 96-104. https://doi.org/10.1080/13880200701734810

[21] Khalaf Allah, H., et al. (2021) Biochemical Effects of Nigella Sativa (Black cumin)on Glucose and Lipid Profile among Sudanese diabetic patients. Open Access Library Journal, 8, Article No. e7500.

[22] Subash Babu, P., Prabuseenivasan, S. and Ignacimuthu, S. (2007) Cinnamaldehyde-A Potential Antidiabetic Agent. Phytomedicine, 14, 15-22.

https://doi.org/10.1016/j.phymed.2006.11.005

[23] Chen, Y. (1981) Pharmacological Studies of Cinnamomum Cassia Bark. Part I. Effects on the Blood and Cardiovascular System (author's transl). Zhong Yao Tong Bao, 6, 32-34.

[24] Mang, B., Wolters, M., Schmitt, B., Kelb, K., Lichtinghagen, R., Stichtenoth, D.O. and Hahn, A. (2006) Effects of a Cinnamon Extract on Plasma Glucose, HbA1c, and Serum Lipids in Diabetes Mellitus Type 2. European Journal of Clinical Investigation, 36, 340-344. https://doi.org/10.1111/j.1365-2362.2006.01629.x

[25] Blevins, S.M., Leyva, M.J., Brown, J., Wright, J., Scofield, R.H. and Aston, C.E. 
(2007) Effect of Cinnamon on Glucose and Lipid Levels in Non Insulin-Dependent Type 2 Diabetes. Diabetes Care, 30, 2236-2237. https://doi.org/10.2337/dc07-0098

[26] Nikbakht, M. and Gheatasi, I. (2006) Evaluation of the Effect of Hydroalcoholic Extract of Citrullus colocynthis in Normoglycemic and Streptozocine (STZ) Induced Diabetic Male Rats. Armaghane Danesh Bimonthly Journal, 11, 63-71.

[27] Huseini, H.F., Darvishzadeh, F., Heshmat, R., Jafariazar, Z., Raza, M. and Larijani, B. (2009) The Clinical Investigation of Citrullus colocynthis (L.) Schrad Fruit in Treatment of Type II Diabetic Patients: A Randomized, Double Blind, Placebo-Controlled Clinical Trial. Phytotherapy Research, 23, 1186-1189.

https://doi.org/10.1002/ptr.2754

[28] Babu, P.S. and Srinivasan, K. (1997) Influence of Dietary Capsaicin and Onion on the Metabolic Abnormalities Associated with Streptozotocin Induced Diabetes Mellitus. Molecular and Cellular Biochemistry, 175, 49-57. https://doi.org/10.1023/A:1006881027166

[29] El-Demerdash, F.M., Yousef, M.I. and El-Naga, N.I. (2005) Biochemical Study on the Hypoglycemic Effects of Onion and Garlic in Alloxan-Induced Diabetic Rats. Food and Chemical Toxicology, 43, 57-63. https://doi.org/10.1016/j.fct.2004.08.012

[30] Alami, Z., Aynaou, H., Alami, B., Hdidou, Y. and Latrech, H. (2015) Herbal Medicines Use among Diabetic Patients in Oriental Morrocco. Journal of Pharmacognosy and Phytotherapy, 7, 9-17. https://doi.org/10.5897/JPP2014.0338

[31] Awad, A., Al-Rabiy, S. and Abahussain, E. (2008) Self Medication Practices among Diabetic Patients in Kuwait. Medical Principles and Practice, 17, 315-320. https://doi.org/10.1159/000129612

[32] Kumar, D., Bajaj, S. and Mehrota, R. (2006) Knowledge, Attitude, and Practice of Complementary and Alternative Medicines for Diabetes. Public Health, 120, 705-711. https://doi.org/10.1016/j.puhe.2006.04.010

[33] Argaez-Lopez, N.W.N.H., Kumate-Rodriguez, J., Cruz, M., Talavera, J. and Rivera-Arce, E. (2003) The Use of Complementary and Alternative Medicine in Type 2 Diabetic Patients in Mexico. Diabetes Care, 26, 2470-2471.

https://doi.org/10.2337/diacare.26.8.2470 